\title{
Application of grey-based DEMATEL technique in designing of the aggregate green supply chain management's model
}

\author{
Adel Azar ${ }^{a}$ and Davood Andalib Ardakani ${ }^{b^{*}}$
}

${ }^{a}$ Professor of Management Science, Tarbiat Modares University, Tehran, Iran ${ }^{b}$ Ph. D. candidate of Industrial Management, Iran, Tarbiat Modares University C H R ON I C L E

Article history:

Received December 10, 2013

Received in revised format

10 March 2013

Accepted March 122014

Available online

March 152014

Keywords:

Green Supply chain management

Grey-based DEMATEL Technique

Yazd Steel Industry

\section{Introduction}

In the 21 st century, industrial development has been replaced by Sustainable Development (Diabat \& Govindan, 2011). Nowadays, sustainable development in each country depends on efficient utilization of existing resources. Hence, the governments deal with this issue through various actions such as green law enforcement, the use of environmentally friendly raw materials in manufacturing and industrial centers, reducing the use of oil and fossil energy resources, paper recycling, reuse of waste, etc. (Zhu \& Sarkis, 2007; Diabat \& Govindan, 2011). Obviously, organizations need to adopt green practices to comply with the laws and regulations (Bose \& Pal, 2012). So, because of the governmental regulations, environmental standards and growing demand for green products, the new concept of "green supply chain" is emerged (Giunipero et al., 2012; Chan et al., 2012; Berns et al., 2009; Foerstl et al., 2010; Walker et al., 2008). The nascent concept of "green supply chain management" (GSCM) has started to gain more attraction (Olugo et al., 2011; Chien \& Shih, 2007; Diabat \& Govindan, 2011); whereas, GSCM comprises many steps of the product life cycle from

* Corresponding author. Tel.: +0989131523854

E-mail addresses: davood.andalib@gmail.com (D. Andalib Ardakani)

(C) 2014 Growing Science Ltd. All rights reserved. doi: $10.5267 /$ j.uscm.2014.3.001 
design to recycling and may be dependent on a variety of environmentally oriented tools such as design for the environment and life cycle analysis. GSCM encompasses components of environmental management as well as closed-loop supply chains, which integrates design, operations, and control of a system for maximizing value over life cycle of a product including value recovery from return/disposal at the end of its use (Bose \& Pal, 2012).

The purpose of GSCM implementation into business activities is to concurrently improve environment and economic performance (Diabat \& Govindan, 2011). Since one of the important goals of supply chain management is to improve supply chain performance (Cai et al., 2009; Bose \& pal, 2012), several studies analyze the effect of GSCM on environmental and organization performance (Testa \& Iraldo, 2010). These studies attempt to conclude that green supply chain can influence companies' profit or even competitive advantages (e.g. Zhu \& Sarkis, 2004). Bowen et al. (2001) argued that financial incentive is the major driver force for implementing green supply chain. Vachon and Klassen (2008) concluded that a correlation exists between environmental performance and competitive advantage in their survey. Rao and Holt (2005) investigated the relationship between green supply chain management practices and firms' competitiveness and confirmed that a positive relationship exists. Chiou et al. (2011) focused only on the Taiwanese market and they concluded that the relationship between GSCM and organizational performance is positive. Notwithstanding the huge amount of studies in the literature in relation to the above, designing a green supply chain model seems to be missing. Steel Industry is critical to many developing countries and spatially in Iran, and it has significant environmental burdens on them. In this paper, we try to model the GSCM of Yazd steel industry as one of the most important Iranian provinces are producing steel.

In order to achieve this model, we will study literature to find out factors related to green supply chain management of the Yazd steel industry. From this foundation, a model of GSCM based on organizational performance measures will be developed with a grey-based DEMATEL technique. These initial findings and results will provide initial insights for management and policy makers in Iran and potentially other developing countries with relatively immature GSCM and general sustainability practices.

\section{Literature}

The growth in the green supply chain literature goes back to the early 1990s (Diabat \& Govindan, 2011). With the advent of issues such as corporate environmental management, environmentally conscious manufacturing strategy (Zhu \& Sarkis, 2006), rising energy prices, the limits of available resources (not renewable), climate change, objectives in terms of reducing emissions (liquid, solid, and gaseous), and concerns for improving the quality of life, supply chain management has been redefined (Diabat \& Govindan, 2011) and it has been integrated with environmental management practices. Based on these issues, the traditional supply chain has been extended to include the afteruse phase of the products. This after-use phase cannot achieve its objectives in isolation and there is a need to develop an integrated approach for planning and controlling the features and manners in which materials flow within the supply chain. This integrated approach is embedded into green supply chain management (Olugu et al., 2011). Obviously, organizations need to adopt green practices to comply with the laws and regulations (Bose \& Pal, 2012). Holt and Ghobadian (2009) concluded that there are seven categories of initiatives for greening supply chain: governments, trade associations and sector bodies, partnership groups, individual companies, business support organizations, not-for-profit green business-support organizations, and green business clubs (Diabat $\&$ Govindan, 2011). Susana et al. (2011) divided drivers into three types of operational (Bayraktar et al., 2009), economic (Rao \& Holt, 2005) and environmental (Pochampally et al., 2009) terms. According to Zhu and Sarkis (2004), the economic performance is the most important driver for enterprises, which seeks to implement environmental management practices (Azevedo et al., 2011). In addition, many companies consider environmental management practices for greening SC to maintain competitive advantage (Rao \& Holt, 2005; Linton et al., 2007; Azevedo et al., 2011). The 
scope of green supply chain includes environmental management, closed-loop supply chain, and a broad perspective of generating value for the organization and society (Bose \& Pal, 2012). However, green supply chain management is defined as the totality of green purchasing, green manufacturing and material management, green distribution and marketing, and finally reverse logistics (Hervani et al., 2005; Linton et al., 2007; Zhu \& Sarkis, 2006; Olugu et al., 2011). This is in line with the explanation given by Vachon and Klassen (2008) that suppliers, manufacturers and customers have to work together towards the reduction of environmental effects from production processes and products (Olugu et al., 2011). Nevertheless, other studies concluded that designing is one of the most important issues for greening the supply chain (Azevedo et al., 2011; Diabat \& Govindan, 2011). Accordingly, Srivastava (2007) defines GSCM as "integrating environmental thinking into SCM, including product design, material sourcing and selection, manufacturing processes, delivery of the final product to the consumers as well as end-of-life management of the product after its useful life" (Azevedo et al., 2011). Based on these factors, the schematic echelons involved in a green supply chain management is presented in Fig. 1.

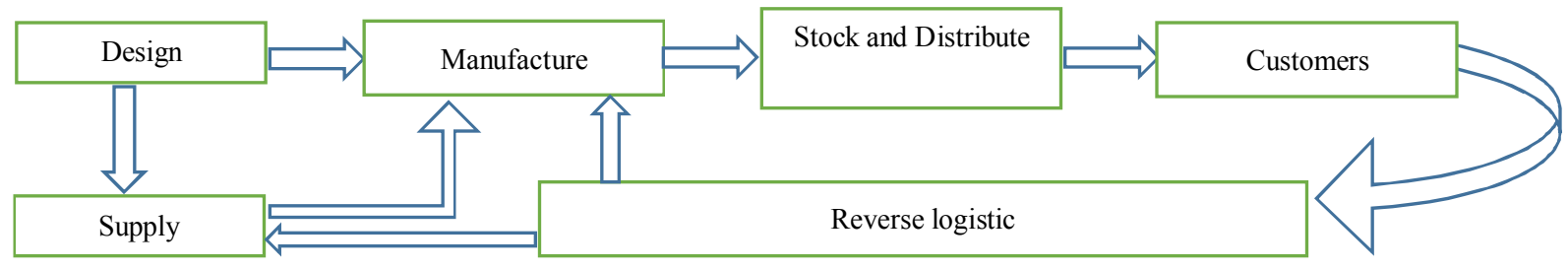

Fig. 1. Schematic summarizing GSCM activities

Pun (2006) investigated the critical processes and factors that affect Environmental Management System (EMS) planning and proposed a five-stage EMS planning framework starting from strategy formulation to system implementation and evaluation (Diabalt \& Govindan, 2011). Hervani et al. (2005) identified more than 40 metrics to measure the environmental performance of a company, ranging from air emissions to energy recovery and recycling (Diabalt \& Govindan, 2011). Sarkis (2003) refers to the following production process characteristics, which impact the greening of an SC: (i) the process's capacity to include certain materials; (ii) the possibility of integrating reusable or remanufactured items into the system; and (iii) the design for waste minimization (energy, water, raw materials and non-product output) (Azevedo et al., 2011). Susana et al. (2011) stated that the proposed green practices are deployed at three levels of upstream, midstream and downstream (Azevedo et al., 2011).

Table 1

The Factors of Green Supply Chain Management's Model

\begin{tabular}{lll}
\hline Echelons & Factors & References \\
\hline Supply & Environmental collaboration with suppliers (a1) & Azevedo et al., 2011 \\
& Encouraging supplier to adopt more environmentally friendly & Holt \& Ghobadian, 2009 \\
& Environmental monitoring of suppliers (a3) & Paulraj, 2009 \\
\hline Design & Eco-design (Green design) (a4) & Diabat \& Govindan, 2011' Susana et al., 2011 \\
& Green process design (a5) & Bose \& Pal, 2012 \\
\hline Manufacture & Developing environmentally friendly products (a6) & Gonzalez et al., 2008 \\
& Implementing internal environmentally friendly operations (a7) & Vachon, 2007 \\
& Getting recognition for environmentally positive behavior (a8) & Zhu et al., 2008 \\
\hline Stock and Distribute & Stock (a9) & Zhu et al., 2005 \\
& Transportation (a10) & Holt \& Ghobadian, 2009 \\
\hline Customers & Environmental collaboration with customers (a11) & Azevedo et al., 2011 \\
& To use environmentally friendly practices with customers (a12) & Holt \& Ghobadian, 2009 \\
\hline Reverse logistic & Reverse logistic (a13) & Guide \& Wassenhove, 2006: Bose \& Pal, 2012 \\
\hline Green supply chain & Environmental performance (a14) & Dües et al., 2012 \\
performance & Economic Performance (a15) & Olugu \& Wong, 2012 \\
\hline
\end{tabular}


As we can observe from Table 1, the green factors that are the focus of this study are not only those that are internal to the company but also the ones, which transcend the company's boundaries involving suppliers and customers.

\section{Methodology}

In this research, initial work involves interviews and meetings to gain an understanding of the problem situation. Then, with reviewing literature, we construct pairwise matrix for gathering data. Moreover, to build, to structure and to illustrate the causal relationships among different identified GSCM's factors, grey-based DEMATEL technique is used, which is a comprehensive technique for building and analyzing a structural model involving causal relationships through matrices or digraphs between a set of factors. The matrices or digraphs portray relationships between system's components with strengths of relationships amongst these relationships quantitatively portrayed. The DEMATEL method assumes a system contains a set of components $c=\left\{c_{i} \mid i=1,2, \ldots, n\right\}$, with pairwise relations, which can be evaluated. In order to apply DEMATEL effectively, this paper proposes the following four steps:

For the first stage in the process, we have multiple sub-steps $1 \mathrm{a}-1 \mathrm{~d}$.

Step 1a: Define a grey pairwise influence comparison scale for the components,

Step 1b: Develop the grey direct-relation matrix $X$ by having evaluators introduce the grey pairwise influence relationships $\left(\otimes x_{i j}^{k}\right)$ between the components in a $n \times n$ matrix. All the principal diagonal elements are initially set to a crisp value of zero (" $N "=$ no influence),

Step 1c: Convert the grey direct-relation matrix into a crisp matrix $Z$ based on the modified-factors process as exemplified by Eqs. (1)-(4).

Let us define $\otimes x_{i j}^{p}$ as the grey number for an evaluator (decision maker) $p$, which would evaluate the effect of factor $i$ on a factor $j$. Also, $\otimes x_{i j}^{p}$ and $\bar{\otimes} x_{i j}^{p}$ are respectively, the lower and upper grey values by an evaluator $p$ for the relationship evaluation between factor $i$ to a factor $j$.

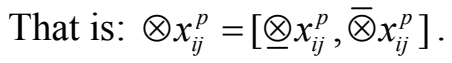

The modified-factors method involves three-step procedure described as follows:

(1) normalization

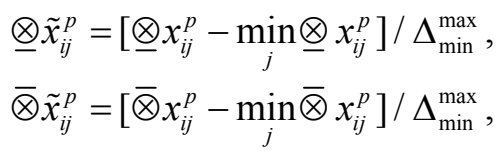

where $\Delta_{\min }^{\max }=\max _{j} \bar{\otimes} x_{i j}^{p}-\min _{j} \otimes x_{i j}^{p}$.

(2) Determine the total normalized crisp value as follows,

$$
Y_{i j}^{p}=\frac{\left(\underline{\otimes} \tilde{x}_{i j}^{p}\left(1-\otimes \underline{x_{i j}^{p}}\right)+\left(\bar{\otimes} \tilde{x}_{i j}^{p} \times \bar{\otimes} \tilde{x}_{i j}^{p}\right)\right)}{\left(1-\underline{\otimes} \tilde{x}_{i j}^{p}+\bar{\otimes} \tilde{x}_{i j}^{p}\right)}
$$

(3) Compute final crisp values

$$
z_{i j}^{p}=\min _{j} \otimes x_{i j}^{p}+Y_{i j}^{p} \Delta_{\min }^{\max }
$$

The process will need to be completed for each of the evaluators' direct-relation matrices. If more than one evaluator exists, go to step 1d, otherwise go to step 2. 
Step 1d: Evaluator weightings, for aggregation purposes, for each evaluator need to be determined. Either simple averaging (Eq. (6)) or weighted averaging (Eq. (7)) can be applied to calculate an aggregate score. We will utilize Eq. (7), which requires determination of evaluator weightings, and it can be defined by grey linguistic scale values for each evaluator $p\left(\otimes w_{p}\right)$. Grey scaled evaluation weightings are required to crisp and sum to 1 as shown in Eq, (7).

$$
\begin{aligned}
z_{i j} & =\frac{1}{p}\left(z_{i j}^{1}+z_{i j}^{2}+\ldots+z_{i j}^{p}\right), \\
z_{i j} & =w_{i} z_{i j}^{1}+w_{2} z_{i j}^{2}+\ldots+w_{p} z_{i j}^{p} \text { such that } \sum_{i=1}^{p} w_{i}=1,
\end{aligned}
$$

where $z_{i j}$ is the overall crisp evaluation for the relationship between factors $i$ and $j, z_{i j}^{p}$ is the crisp evaluation the relationship between factor $i$ and $j$ by evaluator $p, w_{p}$ is the crisp evaluator weight assigned to evaluator $p$ derived from the grey scale weight for each evaluator $\left(\otimes w_{p}\right)$.

Step 2: On the basis of the overall crisp direct-relation matrix $Z$, the normalized direct-relation matrix $N$ can be obtained through Eq. (8) and Eq. (9):

$$
\begin{aligned}
& N=s \cdot N \\
& s=\frac{1}{\max _{1 \leq i \leq n} \sum_{j=1}^{n} z_{i j}}, i, j=1,2, \ldots, n
\end{aligned}
$$

Step 3: Determine the total relation matrix (T) by Eq. (10) where $I$ represents an $n \times n$ identity matrix, $T=N+N^{2}+N^{3}+\cdots=\sum_{i=1}^{\infty} N^{i}=N(I-N)^{-1}$

Step 4: Develop the causal influence and digraph diagram in DEMATEL based on the following three sub-steps:

Step 4a: Determine row $\left(R_{i}\right)$ and column $\left(D_{j}\right)$ sums for each row $i$ and column $j$ from the total relation matrix $(\mathrm{T})$, that is:

$$
\begin{aligned}
& R_{i}=\sum_{j=1}^{n} t_{i j} \quad \forall i, \\
& D_{j}=\sum_{i=1}^{n} t_{i j} \quad \forall j .
\end{aligned}
$$

The row values $\mathrm{R}_{i}$ are the overall direct and indirect effect of a factor $i$ on the model. Similarly, the column values $D_{j}$ represent the overall direct and indirect effects of all factors on factor $j$.

Step 4b: Determine the overall importance or prominence $\left(P_{i}\right)$ of a factor $i$ and net effect $\left(E_{i}\right)$ of factor $i$ using Eq. (13) and Eq. (14).

$$
\begin{aligned}
& P_{i}=\left\{R_{i}+D_{j} \mid i=j\right\} \\
& E_{i}=\left\{R_{i}-D_{j} \mid i=j\right\}
\end{aligned}
$$

The larger the value of $P_{i}$, the greater the overall prominence (visibility/importance/influence) of factor $i$ in terms of overall relationships with other factors, If $E_{i}>0$ then factor is a net cause, foundation, for the model. If $E_{i}<0$, then factor $i$ is reliant on (net effect of) implementation or 
operation of other factors (Tzeng et al., 2007). These values may then be plotted onto a twodimensional axis for each GSDP.

Step 4c: A digraph relationship can be determined for GSCM's model of case study. To complete this step a threshold value $\theta$ should be determined by the evaluators, experts or the analysts (Liou et al., 2007). If $t_{i j} \geq \theta$, then factor $i$ influences or causes factor $j$ and a directed arrow is incorporated into the analysis.

\section{Results}

In our case, we have utilized a five level scale with the following scale items: $\mathrm{N}$ (no influence), VL (very low influence), L (low influence), H (high influence), and VH (very high influence). The grey scales for these linguistic values are defined in the case application. There are 13 mines in Yazd that they provide steel's material. Yazd steel industry produces more steel's material than any other provinces in Iran. It produces about $80 \%$ of steel's material in Iran. The main products of the Yazd steel industry are iron ore concentrate phosphate (Apatite), concentrates lump and fine ore, pellet, sponge iron and rolling. More than 43 percent of products in Yazd's steel industry are exported to foreign countries. Ten percent of the products are consumed in Yazd companies, and the rest is sent to companies in Iran. In our initial step of the process, we have provided 10 experts in the field of Steel Industry to complete pairwise matrices. Table 2 shows the weighted and aggregate data in Yazd Steel Industry.

Table 2

The weighted aggregate data in Yazd Steel Industry

\begin{tabular}{|c|c|c|c|c|c|c|c|c|c|c|c|c|c|c|c|}
\hline factor & a1 & a2 & a3 & a4 & $\mathrm{a} 5$ & a6 & a7 & a8 & a9 & a10 & a11 & a12 & $\mathrm{a} 13$ & a14 & a15 \\
\hline a1 & 0,0 & $0.1, .6$ & $0.1, .6$ & $0.4,1$ & $0.3, .9$ & $0.4,1$ & $0.4,1$ & $0.4,1$ & $0.4,1$ & $0.7,1$ & $0.4,1$ & $0.6,1$ & $0.2,8$ & $0.6,1$ & $0.7,1$ \\
\hline a2 & $0.1, .6$ & 0,0 & 0,4 & 0,4 & 0,4 & $0, .4$ & 0,4 & $0, .4$ & $0, .4$ & $0.1, .6$ & 0,4 & $0, .4$ & 0,4 & 0,4 & 0,4 \\
\hline a3 & $0.1,6$ & $0.1, .6$ & 0 & $0, .4$ & 0,4 & $0.1, .6$ & $0.2,8$ & $0.1, .6$ & $0, .4$ & $0, .4$ & $0, .4$ & $0.2,8$ & $0, .4$ & $0.3,9$ & $0.3,9$ \\
\hline a4 & $0.3, .9$ & $0.2, .8$ & $0.1, .6$ & 0,0 & $0.4,1$ & $0.7,1$ & $0.4,1$ & $0.4,1$ & $0, .4$ & 0,4 & $0.4,1$ & $0.4,1$ & $0.7,1$ & $0.6,1$ & $0.6,1$ \\
\hline a5 & $0.3, .9$ & $0, .4$ & $0.1, .6$ & $0, .4$ & 0,0 & $0.3, .9$ & $0.9,1$ & 1,1 & $0.1, .6$ & $0.1, .6$ & $0.2, .8$ & $0.2, .8$ & $0.4,1$ & 1,2 & $0.9,1$ \\
\hline a6 & $0.4,1$ & 0,4 & $0.1, .6$ & $0.2, .8$ & $0.3, .9$ & 0,0 & $0.4,1$ & $0.6,1$ & 0,4 & 0,4 & $0.8,1$ & $0.8,1$ & 1,1 & $0.6,1$ & $0.6,1$ \\
\hline a7 & $0.3, .9$ & $0, .4$ & $0.1, .6$ & $0.2, .8$ & $0.2, .8$ & $0.2, .8$ & 0,0 & 1,2 & $0.1, .6$ & $0.3, .9$ & $0.3, .9$ & $0.4,1$ & $0.8,1$ & 1,1 & $0.8,1$ \\
\hline a8 & $0.7,1$ & $0.6,1$ & $0.3, .9$ & $0.2, .8$ & $0.3, .9$ & $0.3, .9$ & $0.3, .9$ & 0,0 & $\begin{array}{c}0,4 \\
0,4\end{array}$ & $0.3, .9$ & $0.2, .8$ & $0.2, .8$ & $0.2, .8$ & 1,2 & $0.9,1$ \\
\hline a9 & $0, .4$ & $0, .4$ & $0, .4$ & 0,4 & 0,4 & $0, .4$ & $0.4,1$ & $0.3, .9$ & 0,0 & $0.6,1$ & $0.2, .8$ & $0.2, .8$ & 0,4 & $0.2, .8$ & $0.1, .6$ \\
\hline a10 & $0.6,1$ & $0, .4$ & $0, .4$ & $0, .4$ & 0,4 & $0, .4$ & 1,1 & $0.7,1$ & $0.7,1$ & 0,0 & $0.2, .8$ & $0.4,1$ & $0.4,1$ & $0.4,1$ & $0.4,1$ \\
\hline a11 & $0.1, .6$ & $0.1, .6$ & $0.1, .6$ & $0.6,1$ & $0.2, .8$ & $0.4,1$ & $0.3, .9$ & $0.4,1$ & $0.3, .9$ & $0.6,1$ & 0,0 & $0.9,1$ & $0.6,1$ & $0.4,1$ & $0.7,1$ \\
\hline a12 & 0,4 & $0.1, .6$ & $0, .4$ & $0.2, .8$ & $0.2, .8$ & $0, .4$ & 0.3 & $0.7,1$ & $0.2, .8$ & $0.6,1$ & $0.6,1$ & 0,0 & $0.7,1$ & $0.4,1$ & $0.3, .9$ \\
\hline a13 & 0,4 & $0.2, .8$ & $0, .4$ & $0.2, .8$ & $0.4,1$ & $0.1, .6$ & $0.4,1$ & $0.4,1$ & $0.3, .9$ & $0.6,1$ & $0.2, .8$ & $0.4,1$ & 0,0 & $0.2, .8$ & $0.4,1$ \\
\hline a14 & $0.8,1$ & $0.6,1$ & $0.7,1$ & $0.4,1$ & $0.4,1$ & $0.3, .9$ & $0.3, .9$ & 1,2 & $0.2, .8$ & $0.2, .8$ & $0.7,1$ & $0.6,1$ & $0.4,1$ & 0,0 & $0.9,1$ \\
\hline a15 & $0.6,1$ & $0.4,1$ & $0.3, .9$ & $0.8,1$ & $0.9,1$ & $0.6,1$ & $0.7,1$ & $0.7,1$ & $0.3, .9$ & $0.6,1$ & $0.4,1$ & $0.4,1$ & $0.3,9$ & $0.9,1$ & 0,0 \\
\hline
\end{tabular}

On the basis of the overall grey direct-relation matrix $Z$, the normalized grey direct-relation matrix $N$ can be obtained through related expressions described in the previous section. Table 3 shows the results of the $N$ matrix for the aggregate data.

Table 3

The normalized aggregate data in Yazd Steel Industry

\begin{tabular}{|c|c|c|c|c|c|c|c|c|c|c|c|c|c|c|c|}
\hline factor & al & a2 & a3 & a4 & a5 & $\mathrm{a} 6$ & a7 & a8 & a9 & a10 & a11 & a12 & a13 & a14 & a15 \\
\hline al & 0,1 & $0, .5$ & $0, .5$ & $.3, .3$ & $2, .4$ & $.3, .2$ & $.2, .4$ & $2, .4$ & $.3, .2$ & $0.5,0$ & $.3,3$ & $.3, .2$ & $.1, .5$ & $.2, .3$ & $.4, .1$ \\
\hline $\mathrm{a} 2$ & $0, .6$ & 0,1 & $0, .6$ & $0, .7$ & $0, .7$ & $0, .6$ & $0, .7$ & $0, .7$ & $0, .6$ & $0, .5$ & $0, .7$ & $0, .7$ & $0, .7$ & $0, .7$ & $0, .7$ \\
\hline a3 & $.0, .6$ & $0, .5$ & 0,1 & $0, .7$ & $0, .7$ & $0, .5$ & $.1, .5$ & $0, .6$ & $0, .6$ & $0, .6$ & $0, .7$ & $.1, .5$ & $0, .7$ & $.1, .5$ & $.2,4$ \\
\hline a4 & $.2, .4$ & $.1, .3$ & $0, .5$ & 0,1 & $.2, .3$ & $.5,0$ & $.2, .4$ & $.2, .4$ & $0, .6$ & $0, .6$ & $.3,3$ & $.2, .3$ & $.3, .2$ & $.2, .3$ & $.3,2$ \\
\hline a5 & $.2, .4$ & $0, .6$ & $0, .5$ & $0, .7$ & 0,1 & $.2, .3$ & $.5,0$ & $.5,0$ & $0, .5$ & $0, .5$ & $.1, .5$ & $.1, .5$ & $.2, .4$ & $.5,0$ & $.5,0$ \\
\hline a6 & $.3, .3$ & $0, .6$ & $0, .5$ & $.1, .5$ & $.2, .4$ & 0,1 & $.2, .4$ & $2, .3$ & $0, .6$ & $0, .6$ & $.5,0$ & $.4,0$ & $.5,0$ & $.2, .3$ & $.3,2$ \\
\hline a7 & $.2, .4$ & $0, .6$ & $0, .5$ & $.1, .5$ & $.1, .5$ & $.1, .4$ & 0,1 & $.5,0$ & $0, .5$ & $.2, .3$ & $.2,4$ & $.2, .3$ & $.4, .1$ & $.5,0$ & $.4,0$ \\
\hline a8 & $.4,, 1$ & $.4,0$ & $.2, .3$ & $.1, .5$ & $.2, .4$ & $.2, .3$ & $.1, .5$ & 0,1 & $0, .6$ & $.2, .3$ & $.1, .5$ & $.1, .5$ & $.1, .5$ & $.5,0$ & $.5,0$ \\
\hline a9 & $0 . .7$ & $0, .6$ & $0, .6$ & $0 . .7$ & $0 . .7$ & 0,6 & $.2,4$ & $.1, .5$ & 0,1 & $.4, .1$ & $.1, .5$ & $.1, .5$ & 0.7 & .1,.6 & $0, .6$ \\
\hline a10 & $.3, .2$ & $0, .6$ & $0, .6$ & $0, .7$ & $0, .7$ & $0, .6$ & $.5,0$ & $.3, .3$ & $.5,0$ & 0,1 & $.1, .5$ & $.2, .3$ & $.2, .4$ & $.2, .4$ & $.2, .3$ \\
\hline a11 & $0, .6$ & $0, .5$ & $0, .5$ & $.3, .2$ & $.1, .5$ & $.3, .2$ & $.1, .5$ & $.2, .4$ & $.2,0$ & $.4, .1$ & 0,1 & $.5,0$ & $.4, .3$ & $.2, .4$ & $.4, .1$ \\
\hline a12 & $0, .7$ & $0, .5$ & $0, .6$ & $.1, .5$ & $.1, .5$ & $0, .6$ & $.1, .5$ & $.3, .3$ & $.1, .4$ & $.4, .1$ & $.3,2$ & 0,1 & $.3, .2$ & $.2, .4$ & $.2, .4$ \\
\hline a13 & $0, .7$ & $0, .3$ & $0, .6$ & $.1, .5$ & $.2, .3$ & $0, .5$ & $.2, .4$ & $.2, .4$ & $.2, .3$ & $.4, .1$ & $.1, .5$ & $.2, .3$ & 0,1 & $.1, .6$ & $.2, .3$ \\
\hline a14 & $.5,0$ & $.4,0$ & $.5,0$ & $.3, .3$ & $.2, .3$ & $.2, .3$ & $.1, .5$ & $.5,0$ & $.1, .4$ & $.1, .4$ & $.4, .1$ & $.3,2$ & $.2, .4$ & 0,1 & $.5,1$ \\
\hline a15 & $.3, .2$ & $.3, .1$ & $.2, .3$ & $.5,0$ & $.5,0$ & $.4, .1$ & $.3, .2$ & $.3, .3$ & $.2, .3$ & $.4, .1$ & $.3,3$ & $.2, .3$ & $.1, .5$ & $.4, .1$ & 0,1 \\
\hline
\end{tabular}


The total relation matrix $(T)$ is determined by Eq. (8). The case study total relation matrix is shown in Table 4.

\section{Table 4}

The grey direct-relation matrix for GSCM factor by the Aggregated model

\begin{tabular}{|c|c|c|c|c|c|c|c|c|c|c|c|c|c|c|c|}
\hline Aggregated & a1 & $\mathrm{a} 2$ & a3 & a4 & $\mathrm{a} 5$ & a6 & a7 & a8 & a9 & a10 & a11 & a12 & a13 & a14 & a15 \\
\hline a1 & 0.26 & 0.18 & 0.20 & 0.26 & 0.28 & 0.24 & 0.27 & 0.34 & 0.22 & 0.20 & 0.23 & 0.28 & 0.28 & 0.36 & 0.31 \\
\hline a2 & 0.22 & 0.21 & 0.20 & 0.26 & 0.28 & 0.23 & 0.27 & 0.34 & 0.20 & 0.19 & 0.23 & 0.27 & 0.28 & 0.35 & 0.31 \\
\hline a3 & 0.22 & 0.18 & 0.23 & 0.25 & 0.28 & 0.23 & 0.26 & 0.33 & 0.19 & 0.19 & 0.22 & 0.27 & 0.27 & 0.35 & 0.30 \\
\hline a4 & 0.25 & 0.20 & 0.22 & 0.32 & 0.32 & 0.30 & 0.31 & 0.37 & 0.22 & 0.21 & 0.26 & 0.30 & 0.34 & 0.39 & 0.35 \\
\hline a5 & 0.25 & 0.21 & 0.22 & 0.29 & 0.35 & 0.27 & 0.35 & 0.42 & 0.22 & 0.21 & 0.26 & 0.31 & 0.32 & 0.44 & 0.37 \\
\hline a6 & 0.24 & 0.20 & 0.22 & 0.28 & 0.30 & 0.29 & 0.30 & 0.38 & 0.22 & 0.21 & 0.29 & 0.31 & 0.35 & 0.39 & 0.34 \\
\hline a7 & 0.25 & 0.21 & 0.23 & 0.30 & 0.32 & 0.27 & 0.34 & 0.44 & 0.23 & 0.22 & 0.26 & 0.31 & 0.36 & 0.43 & 0.38 \\
\hline a8 & 0.25 & 0.22 & 0.22 & 0.29 & 0.31 & 0.26 & 0.30 & 0.41 & 0.22 & 0.22 & 0.26 & 0.31 & 0.31 & 0.45 & 0.39 \\
\hline a9 & 0.22 & 0.18 & 0.20 & 0.26 & 0.28 & 0.23 & 0.27 & 0.34 & 0.23 & 0.20 & 0.22 & 0.27 & 0.28 & 0.35 & 0.30 \\
\hline a10 & 0.23 & 0.19 & 0.20 & 0.27 & 0.29 & 0.24 & 0.28 & 0.35 & 0.24 & 0.23 & 0.23 & 0.28 & 0.29 & 0.36 & 0.31 \\
\hline a11 & 0.23 & 0.19 & 0.21 & 0.28 & 0.30 & 0.25 & 0.28 & 0.36 & 0.22 & 0.21 & 0.28 & 0.34 & 0.30 & 0.38 & 0.35 \\
\hline a12 & 0.22 & 0.18 & 0.20 & 0.26 & 0.28 & 0.24 & 0.27 & 0.34 & 0.20 & 0.20 & 0.24 & 0.31 & 0.31 & 0.36 & 0.31 \\
\hline a13 & 0.23 & 0.19 & 0.21 & 0.27 & 0.30 & 0.25 & 0.28 & 0.35 & 0.21 & 0.23 & 0.24 & 0.28 & 0.32 & 0.37 & 0.33 \\
\hline a14 & 0.30 & 0.25 & 0.27 & 0.31 & 0.34 & 0.28 & 0.32 & 0.44 & 0.24 & 0.23 & 0.29 & 0.33 & 0.34 & 0.46 & 0.39 \\
\hline a15 & 0.27 & 0.24 & 0.25 & 0.35 & 0.38 & 0.29 & 0.35 & 0.42 & 0.25 & 0.26 & 0.28 & 0.33 & 0.34 & 0.44 & 0.41 \\
\hline
\end{tabular}

In the next step, we determine the overall importance or prominence $\left(P_{i}\right)$ of factor $i$ and net effect $\left(E_{i}\right)$ of factor $i$.

\section{Table 5}

The Degree of Prominence and Net Cause/Effect of factors by Yazd Steel Industry

\begin{tabular}{|c|c|c|c|c|c|c|c|c|c|c|c|c|c|c|c|}
\hline factor & a1 & $\mathbf{a 2}$ & a3 & a4 & a5 & a6 & $\begin{array}{ll}\text { a7 } \\
\end{array}$ & a8 & a9 & a10 & a11 & a12 & a13 & a14 & a15 \\
\hline D & 3.7 & 2.6 & 2.9 & 3.5 & 3.9 & 3.0 & 4.5 & 5.4 & 2.9 & 3.2 & 3.5 & 4.0 & 4.5 & 5.4 & 4.7 \\
\hline $\mathbf{R}$ & 3.7 & 3.5 & 3.5 & 3.7 & 4.2 & 4.01 & 4.08 & 4.2 & 3.5 & 3.9 & 3.8 & 3.6 & 3.5 & 4.5 & 4.2 \\
\hline Prominence $\mathbf{D}+\mathrm{R}$ & 7.5 & 6.3 & 6.5 & 7.3 & 8.3 & 7.1 & 8.6 & 9.7 & 6.5 & 7.2 & 7.5 & 7.7 & 8.1 & 10.1 & 9.0 \\
\hline Net Effect D-R & -0.1 & -0.9 & -0.5 & -0.2 & -0.3 & -0.9 & 0.5 & 1.2 & -0.6 & -0.7 & -0.3 & 0.4 & 0.9 & 0.9 & 0.5 \\
\hline
\end{tabular}

These values may then be plotted in a two-dimensional axis for each factor. Fig. 2 shows graphic of the overall prominence and net effect results of factors and the relationship between them.

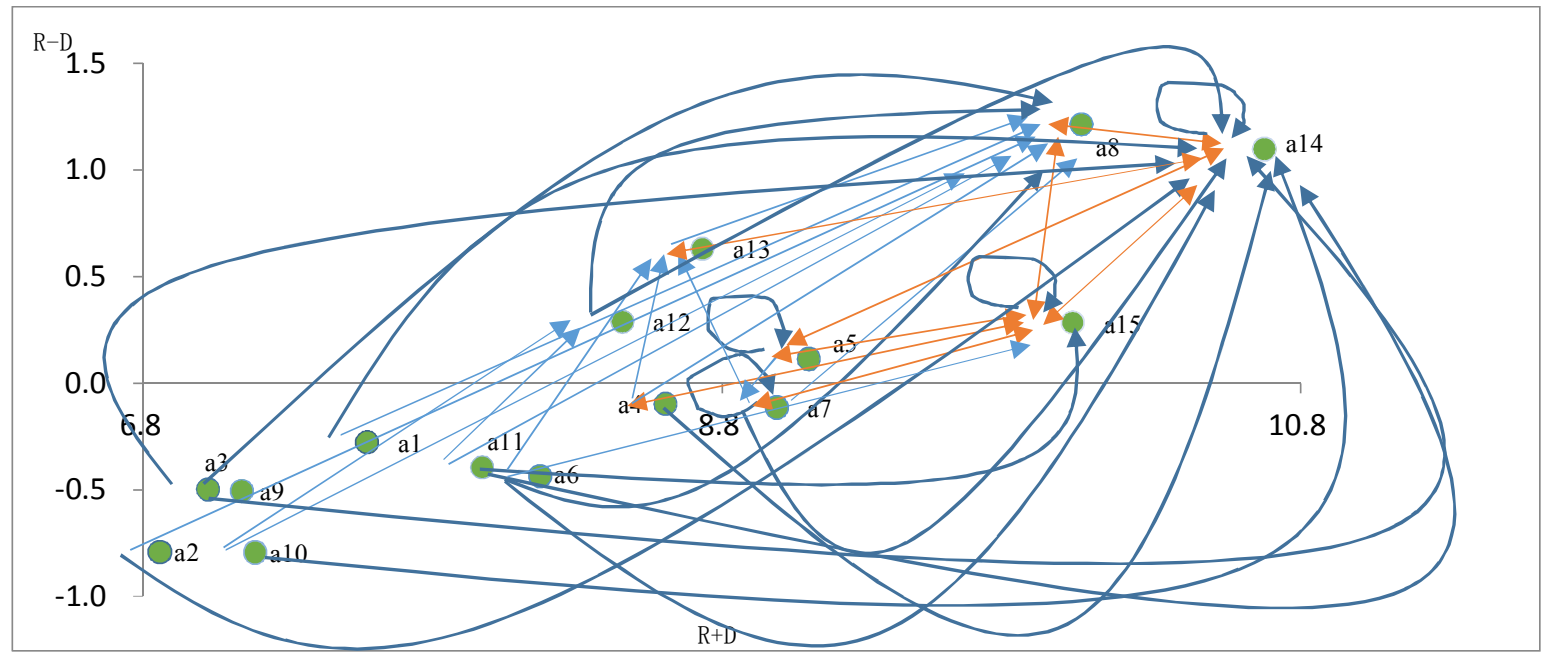

Fig. 2. The graph of aggregate GSCM's Model 


\section{Discussion and conclusion}

The GSCM DEMATEL evaluation reveals two clusters. The "net effect cluster" comprises GSCM factors that mainly influence other GSCM factors, whereas the "net cause cluster" contains GSCM factors that are mainly influenced by others. Fig. 2 illustrates that the aggregate GSCM model informant regards, Environmental performance (a14), Getting recognition for environmentally positive behavior (a8), Economic Performance (a15), Green process design (a5), Reverse logistic (a13) and To use environmentally friendly practices with customers (a12) as net cause factors, and Implementing internal environmentally friendly operations (a7), Eco-design (Green design) (a4), Developing environmentally friendly products (a6), Environmental collaboration with customers (a11), Environmental collaboration with suppliers (a1), Transportation (a10), Stock (a9), Environmental monitoring of suppliers (a3) and Encouraging supplier to adopt more environmentally friendly behaviors (a2) as net effect factors.

Prominence includes the integration of the factors from both a cause (influencing) and effect (resulting) perspective. This analysis will provide us with an ordinal (temporal) perspective on what factors need to be in place initially (require immediate resource investment), and which ones will require attention at a future time. We now separate and evaluate each of these relationships.

As we can observe from the results of Fig. 2, Environmental performance (a14), Getting recognition for environmentally positive behavior (a8), Economic Performance (a15), Green process design (a5) and Implementing internal environmentally friendly operations (a7) are among the most important factors in aggregate GSCM of case study. It's considerable Reverse logistic (a13), Eco-design (Green design) (a4), To use environmentally friendly practices with customers (a12), Developing environmentally friendly products (a6), Environmental collaboration with customers (a11), Environmental collaboration with suppliers (a1), Transportation (a10), Stock (a9), Environmental monitoring of suppliers (a3) and Encouraging supplier to adopt more environmentally friendly behaviors (a2) are not so important factor influencing on GSCM model. The clusters indicated by Fig. 2 are summarized in Table 5.

Table 5

Allocation of factors into cause-effect and Prominence-Not prominence clusters

\begin{tabular}{lcc}
\hline & Not Prominence cluster & Prominence cluster \\
\hline Cause cluster & a13, a12 & a14, a8, a15, a5 \\
Effect cluster & a4, a6, a11, a1, a10, a9, a3, a2 & a7 \\
\hline
\end{tabular}

\section{References}

Azevedo, S. G., Carvalho, H., \& Cruz Machado, V. (2011). The influence of green practices on supply chain performance: a case study approach. Transportation research part E: logistics and transportation review, 47(6), 850-871.

Bayraktar, E., Demirbag, M., Koh, S. C., Tatoglu, E., \& Zaim, H. (2009). A causal analysis of the impact of information systems and supply chain management practices on operational performance: evidence from manufacturing SMEs in Turkey. International Journal of Production Economics, 122(1), 133-149.

Berns, G. S., Moore, S., \& Capra, C. M. (2009). Adolescent engagement in dangerous behaviors is associated with increased white matter maturity of frontal cortex. PloS one, 4(8), e6773.

Bose, I., \& Pal, R. (2012). Do green supply chain management initiatives impact stock prices of firms?. Decision support systems, 52(3), 624-634.

Bowen, F. E., Cousins, P. D., Lamming, R. C., \& Farukt, A. C. (2001). The role of supply management capabilities in green supply. Production and operations management, 10(2), 174189. 
Cai, J., Liu, X., Xiao, Z., \& Liu, J. (2009). Improving supply chain performance management: A systematic approach to analyzing iterative KPI accomplishment. Decision Support Systems, 46(2), 512-521.

Chan, C. Y., St John, A. L., \& Abraham, S. N. (2013). Mast cell interleukin-10 drives localized tolerance in chronic bladder infection. Immunity, 38(2), 349-359.

Chan, K. M., Guerry, A. D., Balvanera, P., Klain, S., Satterfield, T., Basurto, X., ... \& Woodside, U. (2012). Where are cultural and social in ecosystem services? A framework for constructive engagement. BioScience, 62(8), 744-756.

Chien, M. K., \& Shih, L. H. (2007). An empirical study of the implementation of green supply chain management practices in the electrical and electronic industry and their relation to organizational performances.

Chiou, T. Y., Chan, H. K., Lettice, F., \& Chung, S. H. (2011). The influence of greening the suppliers and green innovation on environmental performance and competitive advantage in Taiwan. Transportation Research Part E: Logistics and Transportation Review, 47(6), 822-836.

Diabat, A., \& Govindan, K. (2011). An analysis of the drivers affecting the implementation of green supply chain management. Resources, Conservation and Recycling, 55(6), 659-667.

Dües, C. M., Tan, K. H., \& Lim, M. (2013). Green as the new Lean: how to use Lean practices as a catalyst to greening your supply chain. Journal of cleaner production, 40, 93-100.

Foerstl, K., Reuter, C., Hartmann, E., \& Blome, C. (2010). Managing supplier sustainability risks in a dynamically changing environment-Sustainable supplier management in the chemical industry. Journal of Purchasing and Supply Management, 16(2), 118-130.

Giunipero, L. C., Hooker, R. E., \& Denslow, D. (2012). Purchasing and supply management sustainability: Drivers and barriers. Journal of Purchasing and Supply Management, 18(4), 258269.

Gonzalez, P., Sarkis, J., \& Adenso-Diaz, B. (2008). Environmental management system certification and its influence on corporate practices: evidence from the automotive industry. International Journal of Operations \& Production Management, 28(11), 1021-1041.

Guide, V. D. R., \& Wassenhove, L. N. V. (2006). Closed-Loop Supply Chains: An Introduction to the Feature Issue (Part 2). Production and Operations Management, 15(4), 471-472.

Hervani, A. A., Helms, M. M., \& Sarkis, J. (2005). Performance measurement for green supply chain management. Benchmarking: An International Journal, 12(4), 330-353.

Holt, D., \& Ghobadian, A. (2009). An empirical study of green supply chain management practices amongst UK manufacturers. Journal of Manufacturing Technology Management, 20(7), 933-956.

Holt, D., \& Ghobadian, A. (2009). An empirical study of green supply chain management practices amongst UK manufacturers. Journal of Manufacturing Technology Management, 20(7), 933-956.

Linton, J. D., Klassen, R., \& Jayaraman, V. (2007). Sustainable supply chains: an introduction. Journal of Operations Management, 25(6), 1075-1082.

Olugu, E. U., \& Wong, K. Y. (2012). An expert fuzzy rule-based system for closed-loop supply chain performance assessment in the automotive industry. Expert Systems with Applications, 39(1), 375384.

Olugu, E. U., Wong, K. Y., \& Shaharoun, A. M. (2011). Development of key performance measures for the automobile green supply chain. Resources, Conservation and Recycling, 55(6), 567-579.

Paulraj, A. (2009). Environmental motivations: a classification scheme and its impact on environmental strategies and practices. Business Strategy and the Environment, 18(7), 453-468.

Pochampally, K. K., Gupta, S. M., \& Govindan, K. (2009). Metrics for performance measurement of a reverse/closed-loop supply chain. International Journal of Business Performance and Supply Chain Modelling, 1(1), 8-32.

Pun, K. F. (2006). Determinants of environmentally responsible operations: a review. International Journal of Quality \& Reliability Management, 23(3), 279-297.

Rao, P., \& Holt, D. (2005). Do green supply chains lead to competitiveness and economic performance?. International Journal of Operations \& Production Management, 25(9), 898-916. 
Sarkis, J. (2003). A strategic decision framework for green supply chain management. Journal of cleaner production, 11(4), 397-409.

Srivastava, S. K. (2007). Green supply-chain management: a state-of-the-art literature review. International journal of management reviews, 9(1), 53-80.

Testa, F., \& Iraldo, F. (2010). Shadows and lights of GSCM (Green Supply Chain Management): determinants and effects of these practices based on a multi-national study. Journal of Cleaner Production, 18(10), 953-962.

Vachon, S. (2007). Green supply chain practices and the selection of environmental technologies. International Journal of Production Research, 45(18-19), 4357-4379.

Vachon, S., \& Klassen, R. D. (2008). Environmental management and manufacturing performance: the role of collaboration in the supply chain. International Journal of Production Economics, 111(2), 299-315.

Walker, H., Di Sisto, L., \& McBain, D. (2008). Drivers and barriers to environmental supply chain management practices: Lessons from the public and private sectors. Journal of Purchasing and Supply Management, 14(1), 69-85.

Zhu, Q., \& Sarkis, J. (2004). Relationships between operational practices and performance among early adopters of green supply chain management practices in Chinese manufacturing enterprises. Journal of Operations Management, 22(3), 265-289.

Zhu, Q., \& Sarkis, J. (2006). An inter-sectoral comparison of green supply chain management in China: drivers and practices. Journal of cleaner production, 14(5), 472-486.

Zhu, Q., \& Sarkis, J. (2007). The moderating effects of institutional pressures on emergent green supply chain practices and performance. International Journal of Production Research, 45(18-19), 4333-4355.

Zhu, Q., Sarkis, J., \& Geng, Y. (2005). Green supply chain management in China: pressures, practices and performance. International Journal of Operations \& Production Management, 25(5), 449-468.

Zhu, Q., Sarkis, J., \& Lai, K. H. (2008). Green supply chain management implications for "closing the loop". Transportation Research Part E: Logistics and Transportation Review, 44(1), 1-18. 